\title{
Normalization of anti-mullerian hormone level after growth hormone replacement in a patient with congenital growth hormone deficiency: A case study
}

\author{
MacKenzie P Purdy ${ }^{1 *}$, Phoebe H Leonard ${ }^{1}$, Deborah J Rhodes ${ }^{2}$ and Charles C Coddington ${ }^{1}$ \\ ${ }^{1}$ Department of Obstetrics and Gynecology, Division of Reproductive Endocrinology and Infertility, Mayo Clinic, USA \\ ${ }^{2}$ Department of Medicine, Mayo Clinic, USA
}

\begin{abstract}
Objective: To describe a case of congenital growth hormone deficiency in a patient that had return of ovarian function after growth hormone replacement following undetectable levels of anti-mullerian hormone (AMH) level.

Design: Case Study.

Setting: Mayo Clinic.

Patient(s): A 32-year-old woman with congenital growth hormone deficiency (CGHD) was evaluated at Mayo Clinic and noted to have an undetectable AMH level.

Intervention(s): The patient was started on Humatrope at a dose of $0.4 \mathrm{mg}$ daily. Patient was escalated on growth hormone therapy until her IGF-1 levels were within normal range.

Main Outcome Measure(s): Return of cyclical menses and increase in AMH level to normal range.

Results: After 12 months of GH replacement, the patient's menses had returned to regular 28-day cycles and her hypoestrogenic symptoms had resolved. Her GH was adequately replaced with an IGF-1 level of $151 \mathrm{ng} / \mathrm{mL}$. Her AFC had increased to 16 from a previous ultrasound depicting 1 antral follicle and her laboratory tests had returned to normal levels; FSH 7.7IU/L, estradiol $33 \mathrm{pg} / \mathrm{mL}$ and AMH $1.9 \mathrm{ng} / \mathrm{mL}$.

Conclusion: This documents a patient with CGHD and suppressed AMH levels. In this case, GH correction played a significant role in restoring ovarian function. Assessing ovarian reserve status in adolescent patients with CGHD is a key component in their evaluation and may allow for oocyte cryopreservation in young girls that have normalization of ovarian function after treatment. This is important, as there is unclear data on the long term fertility potential of patients with CGHD. $\mathrm{AMH}$ has been shown to be a marker of ovarian reserve in a patient with CGHD which demonstrated a dynamic shift in AMH that was related to the patient's GH status.
\end{abstract}

\section{Introduction}

Growth hormone is involved in diverse areas of the body from linear growth to regulation of male and female infertility. Growth hormone is not only produced by the pituitary but is also produced by the ovary and has been shown to bind to granulosa, theca, and luteal cells promoting steroidogenesis [1,2]. Growth hormone also works through insulin like growth factor-1 by increasing the sensitivity of ovaries to gonadotropins $[3,4]$. Children with growth hormone deficiency are noted to have pubertal delay and typically do not have menarche until growth hormone is replaced [5]. A study looking at 34 patients with CGHD without spontaneous pubertal development had menarche following growth hormone replacement with 12 subsequently developing secondary amenorrhea following discontinuation [6].

Both growth hormone and IFG-1 play a role in the recruitment of ovarian follicles [7]. When $\mathrm{GH}$ is deficient there is a decrease in ovarian sensitivity to FSH leading to monofollicular growth as opposed to a recruitment of a dominant follicle and perhaps decreased stimulation of all antral follicles $[8,9]$. A recent study noted that in women with hypopituitarism, growth hormone replacement lead to increased endometrial thickness and better ovarian response to gonadotropins when undergoing in vitro fertilization [10].

Many patients with growth hormone deficiency require assisted reproductive technology [11]. Assessing a patient's ovarian reserve is very important in order to determine the best treatment option for the patient. Anti-mullerian hormone (AMH) and antral follicle count (AFC) are two markers used to measure ovarian reserve and are important when predicting a patient's fertility [6]. Both are known to decrease with age and can become undetectable following menopause.

Correspondence to: MacKenzie Purdy, MD, Department of Obstetrics and Gynecology, Division of Reproductive Endocrinology and Infertility, Mayo Clinic, 200 1st Street SW, Rochester, MN, USA, Tel: 507-284-9740; E-mail: mackenzie.purdy@mayo.com

Key words: growth hormone, anti-mullerian hormone, antral follicle count, insulin-like growth factor I, ovarian reserve

Received: March 08, 2018; Accepted: March 22, 2018; Published: March 26, 2018 

case study

Patients with premature ovarian insufficiency or diminished ovarian reserve are noted to also have very low AMH and AFC that typically does not improve with any treatment option [12].

To our knowledge there do not appear to be any studies demonstrating a rise in $\mathrm{AMH}$ and AFC following growth hormone replacement in patients with growth hormone deficiency. Here we will present a case of a patient who had CGHD that stopped growth hormone replacement and was noted to have an undetectable $\mathrm{AMH}$ that improved substantially following correction of her growth hormone deficiency; this leading to an incorrect impression that she had a decreased ovarian reserve.

\section{Case presentation}

A 32-year-old woman with congenital growth hormone deficiency (CGHD) was evaluated at our center for multiple comorbidities. The patient had been diagnosed with CGHD at age 6 and was on growth hormone replacement with Humatrope until 2007. After a gastrointestinal illness, she developed IgA nephropathy that was treated with high dose corticosteroids. During this time she discontinued the Humatrope and was noted to be amenorrheic with hypoestrogenic symptoms. Following resolution of the IgA nephropathy, she initiated an oral contraceptive that improved her hypoestrogenic symptoms.

In November of 2009, ovarian reserve testing was done and noted an AFC of one. She did not undergo hormonal evaluation as she was taking oral contraceptives. Her IGF-1 was found to be extremely low at $<25 \mathrm{ng} / \mathrm{mL}$, prompting resumption of Humatrope at a dose of 0.4 mg daily.

In March of 2010, she was evaluated for amenorrhea following discontinuation of the oral contraceptive for 6 months. Repeat evaluation noted a stable AFC of one, an FSH of $12.4 \mathrm{IU} / \mathrm{L}$, and estradiol of $40 \mathrm{pg} / \mathrm{mL}$. Her AMH level using ELISA was undetectable. Despite six months of Humatrope, her IGF-1 remained low at $108 \mathrm{ng} / \mathrm{mL}$. Her dosage was increased to $0.5 \mathrm{mg}$ daily.

\section{Outcome}

In August 2010, after 12 months of Humatrope, her menses had returned to regular 28 day cycles and her hypoestrogenic symptoms had resolved. Her IGF-1 level was noted to be within the normal range at $151 \mathrm{ng} / \mathrm{mL}$. Her AFC increased to 16 and her laboratory tests had returned to normal levels; FSH $7.7 \mathrm{IU} / \mathrm{L}$, estradiol $33 \mathrm{pg} / \mathrm{mL}$, and AMH $1.9 \mathrm{ng} / \mathrm{mL}$.

\section{Discussion}

This case report to our knowledge is the first to document a patient with CGHD and suppressed AMH levels. As previously noted many children with GH deficiency eventually require assistance with reproduction and have decreased fertility. There have been multiple cases demonstrating improvement in fertility with growth hormone replacement, but to date, there have been no studies evaluating the relationship between growth hormone correction and improvement in predictors of ovarian reserve that may allow for a more optimal time to proceed with oocyte cryopreservation [9].

AMH has been shown to be a stable marker of ovarian reserve and is thought to remain stable throughout the menstrual cycle allowing it to be a helpful predictor of a patient's fertility [6]. The typical progression of an AMH value is to decline over a woman's lifetime until undetectable [12]. This study demonstrates that there can be a dynamic shift in AMH and AFC with growth hormone therapy.
Based on this case report it is important to assess the growth hormone status of a patient with CGHD as there may be a limited window to proceed with oocyte cryopreservation that would likely be the most advantageous at an earlier age. Correction allows a patient to proceed with multiple fertility options including immediate assisted reproduction or continue to monitor ovarian reserve as we do not yet know the timeline or likelihood of the AMH and AFC returning to levels consistent with diminished ovarian reserve.

\section{Synopsis}

There is significant improvement in anti-mullerian hormone levels and antral follicle count following correction of growth hormone deficiency.

\section{Capsule summary}

There is significant improvement in AMH following correction of growth hormone deficiency.

\section{Sources of study}

Mayo Clinic

\section{Disclosure of funding/conflict of interest}

No funding received or pertinent conflicts of interest.

\section{References}

1. Hull KL, Harvey S (2001) Growth hormone: roles in female reproduction. J Endocrinol 168: 1-23. [Crossref]

2. Spiliotis BE (2003) Growth hormone insufficiency and its impact on ovarian function. Ann N Y Acad Sci 997: 77-84. [Crossref]

3. Chandrashekar V, Zaczek D, Bartke A (2004) The consequences of altered somatotropic system on reproduction. Biol Reprod 71: 17-27. [Crossref]

4. Chang SY, Tsai MY, Huang FJ, Kung FT (2002) Expression of insulin-like growth factor (IGF), IGF receptor, and IGF-binding protein messenger ribonucleic acids in luteinized granulosa cells from different size follicles after controlled ovarian hyperstimulation. J Assist Reprod Genet 19: 121-126. [Crossref]

5. de Boer JA, Schoemaker J, van der Veen EA (1997) Impaired reproductive function in women treated for growth hormone deficiency during childhood. Clin Endocrinol (Oxf) 46: 681-689. [Crossref]

6. Hehenkamp WJ, Looman CW, Themmen AP, de Jong FH, Te Velde ER, et al. (2006) Anti-Mullerian hormone levels in the spontaneous menstrual cycle do not show substantial fluctuation. J Clin Endocrinol Metab 91:4057-4063. [Crossref]

7. Hull KL, Harvey S (2014) Growth hormone and reproduction: a review of endocrine and autocrine/paracrine interactions. Int J Endocrinol 2014: 234014. [Crossref]

8. Magon N, Agrawal S, Malik S, Babu KM (2011) Growth hormone in the management of female infertility. Indian J Endocrinol Metab 15(Supp13): S246-S247. [Crossref]

9. Adashi EY, Resnick CE, Hurwitz A, Ricciarelli E, Hernandez ER, et al. (1991) Insulinlike growth factors: the ovarian connection. Hum Reprod 6: 1213-1219. [Crossref]

10. Drakopoulos P, Pluchino N, Bischof P, Cantero P, Meyer P (2016) Effect of growth hormone on endometrial thickness and fertility outcome in the treatment of women with panhypopituitarism: a case report. J Reprod Med 61: 78-82. [Crossref]

11. Salle A, Klein M, Pascal-Vigneron V, Dousset B, Leclere J, et al. (2000) Successful pregnancy and birth after sequential cotreatment with growth hormone and gonadotropins in a woman with panhypopituitarism: a new treatment protocol. Fertil Steril 74: 1248-1250. [Crossref]

12. Lunding SA, Aksglaede L, Anderson RA, Main KM, Juul A, et al. (2015) AMH as predictor of premature ovarian insufficiency: a longitudinal study of 120 turner syndrome patients. J Clin Endocrinol Metab 100: E1030-E1038. [Crossref]

Copyright: C2018 Purdy MP. This is an open-access article distributed under the terms of the Creative Commons Attribution License, which permits unrestricted use, distribution, and reproduction in any medium, provided the original author and source are credited. 